\title{
Impactos ambientais causados pela mineração: uma análise da percepção de pequenos mineradores do município de Frei Martinho - PB
}

\author{
Environmental impacts caused by mining: an analysis of the perception of \\ small miningers of the municipality of Frei Martinho - PB
}

\author{
José Jailson Lima Bezerra ', Wennir Bezerra Lira ", Tiago da Costa Silva III
}

\section{RESUMO}

A mineração é uma atividade que gera emprego e renda para muitas comunidades em todo o mundo. Porém, existem problemas diretamente associados ao exercício desta prática, dentre eles está a degradação do meio ambiente, onde as escavações não planejadas podem alterar diversos ecossistemas terrestres e aquáticos. Sabendo-se disso, objetivou-se levantar informações junto aos mineradores do Município de Frei Martinho, Paraíba, sobre as diferentes percepções que eles têm acerca dos impactos ambientais causados pela mineração. Desta forma, entrevistou-se um número de vinte mineradores que estão envolvidos com atividades de extração de minérios nos Sítios Timbaúba e Quixaba, localizados no Município de Frei Martinho. Para a realização das entrevistas, foi utilizado um formulário que apresentava perguntas diretamente relacionadas com a percepção dos mineradores sobre os efeitos negativos que a exploração de minérios exerce no meio ambiente. As respostas atribuídas pelos mineradores foram analisadas quantitativamente. A partir dos dados coletados, foi possível observar que muitos dos mineradores desconhecem alguns pontos relevantes em relação aos danos que a mineração pode causar ao meio ambiente. Assim, torna-se necessário a realização de palestras e outros meios de conscientização por parte das empresas e cooperativas responsáveis pela mineração no Município de Frei Martinho.

Palavras-chave: Impactos Ambientais; Percepção do Minerador; Mineração de Pequeno Porte.

\section{ABSTRACT}

Mining is an activity that generates jobs and income for many communities around the world. However, there are problems directly associated with the practice of this practice, among them is the degradation of the environment, where unplanned excavations can alter several terrestrial and aquatic ecosystems. Knowing this, the objective of this work to gather information from the miners of the Municipality of Frei Martinho, Paraíba, about the different perceptions they have about the environmental impacts caused by mining. In this way, we interviewed a number of twenty miners who are involved in mining activities at the Timbaúba and Quixaba Sites, located in the Municipality of Frei Martinho. For the interviews, a form was used that presented questions directly related to the

\footnotetext{
I Doutorando pelo Programa de Pós-Graduação em Biologia Vegetal. Departamento de Botânica, UFPE. ORCID: https://orcid.org/0000-0003-2081-8304.E-mail: josejailson.bezerra@hotmail.com.

"Técnica em Mineração, IFPB. ORCID: https://orcid.org/0000-0001-7402-5858. E-mail: wennir-liiraa@hotmail.com.

III Professor efetivo, IFPB. ORCID: https://orcid.org/0000-0003-3617-3336. E-mail: tiago.costaa@ifpb.edu.br.
} 
perception of the miners about the negative effects that the exploitation of ores exerts on the environment. The responses attributed by the miners were analyzed quantitatively. From the data collected, it was possible to observe that many of the miners are unaware of some relevant points regarding the damage that mining can cause to the environment. Thus, it is necessary to hold lectures and other means of awareness by the companies and cooperatives responsible for mining in the municipality of Frei Martinho.

Keywords: Environmental impacts; Miner Perception; Small Mining Enterprises.

\section{INTRODUÇÃO}

As atividades relacionadas com a extração de minérios tem se consolidado ao longo dos anos devido a sua importância para a economia de vários países, e consequentemente, tem gerado emprego e renda para muitas pessoas. De acordo com Patrício et al. (2013) o setor mineral tem exercido uma importante função para o desenvolvimento da maioria das cidades de pequeno e médio porte, repercutindo favoravelmente no âmbito social, econômico e administrativo. Estimativas apresentadas por Wanderley et al. (2016) revelam que em 2013, apenas cinco países foram responsáveis por dois terços das exportações globais de minérios, tendo o Brasil ocupando o segundo lugar, respondendo por $14,3 \%$ das exportações de minério no mundo.

Embora a geração de renda seja uma vantagem atrelada a obtenção e comercialização de minérios, existem malefícios ligados a esta prática que devem ser levados em consideração, tendo em vista que as alterações ou impactos advindos da atividade mineral podem provocar maior ou menor impacto, conforme a localização e as formas de extração (PONTES et al., 2013). Segundo Silva (2007) a mineração e a agricultura, junto com a exploração florestal e outras atividades antrópicas, são os causadores de quase todo o impacto ambiental existente na terra, o que implica em sérios problemas para a fauna, a flora e até mesmo para a saúde humana. De acordo com Guimarães e Milanez (2017) os impactos da mineração para o meio ambiente, especialmente no caso do minério de ferro, são severos, como atesta a destruição do pico do Cauê, Itabira, Minas Gerais.

Estes problemas são causados, principalmente, pela necessidade frequente de escavações vultosas para a retirada do bem mineral, que resultam em grandes volumes de 
estéril, provocando impactos negativos significativos para o meio ambiente $(\mathrm{MECHI}$ e SANCHES, 2010). Vieira e Rezende (2015) explicam que a mineração deve ser realizada tendo como princípio o uso racional dos recursos naturais, tomando-se como base os princípios estabelecidos na Política Nacional do Meio Ambiente (PNMA), visando diminuir os danos ambientais. Neste sentido, a conservação dos recursos naturais chama atenção para a busca da exploração racional daqueles recursos (MARTIM e SANTOS, 2013).

Atividades antrópicas têm prejudicado vários ecossistemas terrestres e aquáticos, colocando em risco questões relacionadas com a fauna e a flora brasileira, sendo a biodiversidade um fator de grande importância para o país (MANOEL et al., 2013). Assim, esta pesquisa se concentrou na análise da percepção dos mineradores do município de Frei Martinho, Paraíba, sobre os impactos causados pela atividade mineradora na região, tendo em vista que esta é uma preocupação que abrange vários setores de proteção ambiental. Apesar da dificuldade em encontrar soluções para este caso, o diálogo e a coleta de dados junto aos mineradores do referido município são necessários para servir como subsídio para que novos trabalhos sejam realizados. Desta forma, a presente pesquisa teve como objetivo levantar informações junto aos mineradores do Município de Frei Martinho, Paraíba, sobre as diferentes percepções que eles têm acerca dos impactos ambientais causados pela mineração.

\section{METODOLOGIA}

Esta pesquisa foi realizada a partir da coleta de dados por meio de entrevistas realizadas com mineradores no Município de Frei Martinho, Paraíba, entre os meses de dezembro de 2017 e janeiro de 2018. As respostas atribuídas pelos entrevistados foram analisadas quantitativamente e apresentadas sob a forma de gráficos. 


\subsection{Descrição da área de estudo}

Frei Martinho é um município brasileiro do Estado da Paraíba, localizado na microrregião do Seridó Oriental Paraibano, caracterizado por ser uma região de semiárido com clima de caatinga. Além disso, este município tem um potencial mineral relevante, sendo amplamente explorado ao longo das últimas décadas. Segundo estimativas do IBGE (2017), Frei Martinho tem uma população de 2.990 pessoas, e ocupa uma área territorial de $244,317 \mathrm{~km}^{2}$. A presente pesquisa foi realizada com pequenos mineradores dos Sítios Timbaúba e Quixaba, que trabalham com a extração de minerais de pegmatitos em processos próprios e de terceiros, e cuja principal fonte de renda deles é a atividade mineral.

\subsection{Procedimentos para realizar a pesquisa}

Tendo em vista identificar a percepções dos pequenos mineradores sobre os principais impactos ambientais causados pela mineração no Município de Frei Martinho $P B$, entrevistou-se um número de vinte mineradores que estão envolvidos com atividades de extração de minérios nos Sítios Timbaúba e Quixaba.

Foi utilizado o método de pesquisa conhecido por Survey. De acordo com alguns autores, a pesquisa Survey pode ser descrita como a obtenção de dados ou informações sobre características, ações ou opiniões de determinado grupo de pessoas, indicado como representante de uma população-alvo (FREITAS et al., 2000).

Neste sentido, foi elaborado um formulário tomando-se como base questões relevantes para atender os objetivos gerais e específicos desta pesquisa. O formulário utilizado nas entrevistas apresentava perguntas diretamente relacionadas com a percepção dos mineradores sobre os efeitos negativos que a exploração de minérios exerce no meio ambiente.

No momento da aplicação das entrevistas com os participantes desta pesqui sa, foi repassado o Termo de Consentimento Livre e Esclarecido (TCLE) para que eles analisassem as finalidades descritas da proposta, como também o risco-benefício que sua participação 
poderia ocasionar. O TCLE destacou pontos específicos que assegurasse o sigilo das informações pessoais dos entrevistados, de forma a proteger a privacidade destes.

\subsection{Análise dos resultados}

As respostas atribuídas pelos mineradores durante as entrevistas foram analisadas quantitativamente, levando em consideração todos os aspectos ligados com os impactos negativos causados pela mineração em Frei Martinho - PB e apresentados sob a forma de gráficos.

\section{RESULTADOS E DISCUSSÃO}

Durante as entrevistas realizadas no município de Frei Martinho com os mineradores que exercem suas atividades na referida região (Figura 1), foi possível observar que muitos deles têm conhecimento sobre alguns pontos relevantes em relação aos malefícios que a mineração pode causar no meio ambiente.

Figura 1 - Entrevista realizada com os mineradores do município de Frei Martinho - PB

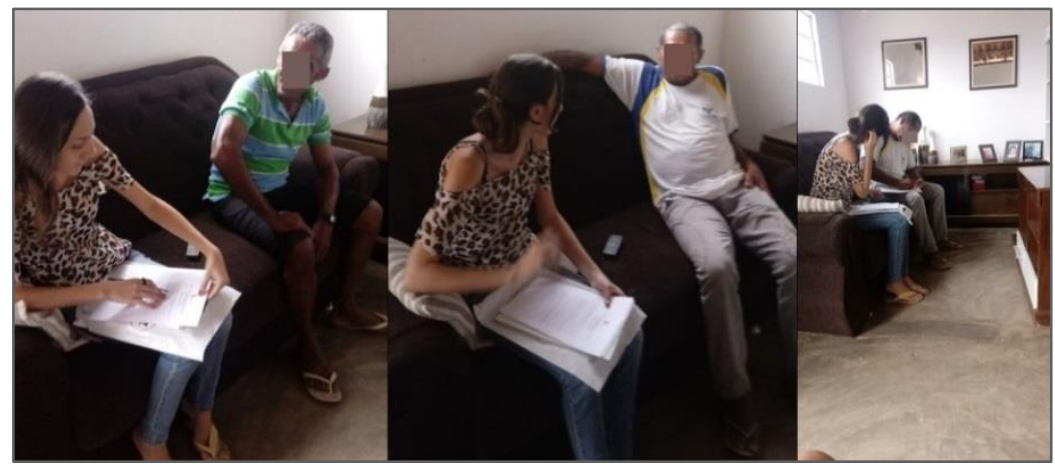

Fonte: Dados da pesquisa, 2018.

Em relação a primeira questão (Q1 - Você tem conhecimento dos problemas ambientais decorrentes das atividades mineradoras em seu Município? Explique.) boa parte dos mineradores relataram prejuízos preocupantes, tais como: desmatamento (80\%), poluição de rios (10\%) e escavações não planejadas (5\%) (Figura 2), tendo em vista que 
muitos indivíduos dependem de forma direta, ou indiretamente, dos ecossistemas naturais para sobreviverem, e as ações antrópicas acabam destruindo seus habitats naturais.

Figura 2 - Percepção dos mineradores acerca dos problemas ambientais causados pela mineração no município de Frei Martinho - PB

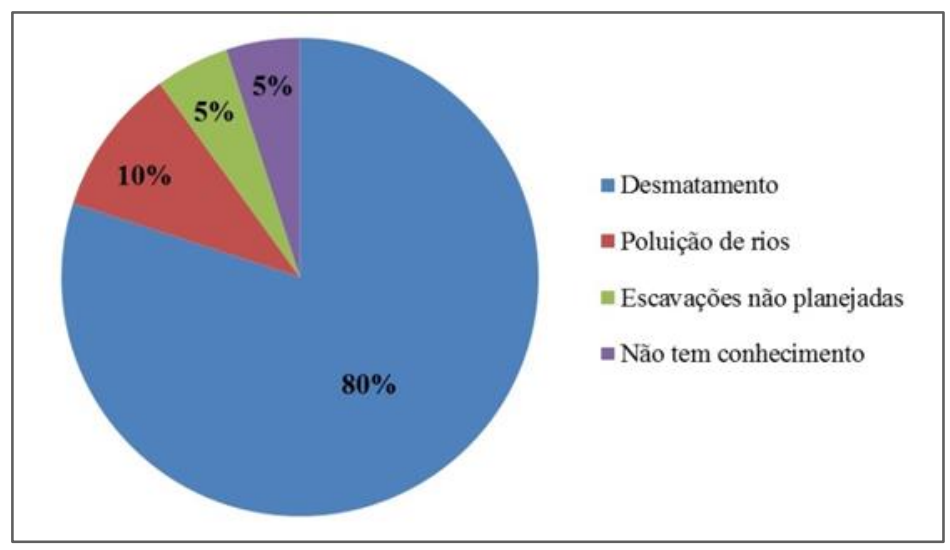

Fonte: Dados da pesquisa, 2018.

Além dos problemas ambientais citados pelos entrevistados desta pesquisa, outros impactos são amplamente conhecidos, tais como: a destruição da mata ciliar, o afugento de animais, a poluição das águas e dos solos, a alteração dos cursos dos rios, bem como de sua profundidade, alterando a velocidade de escoamento dessas águas (ANNIBELLI e SOUZA FILHO, 2006). Como forma de evitar perdas maiores nos ecossistemas, diversos projetos de leis têm sido criados ao longo do tempo para regulamentar estas práticas exploratórias.

A poluição sonora se destaca como sendo outro problema sério associado às atividades mineradoras. Segundo Assis et al. (2011) as detonações de explosivos comprometem o sossego da população local, os estrondos provocados pelas detonações são alarmantes e os abalos que eles vêm causando nas residências são inevitáveis pela proximidade das Minas.

De acordo com a segunda questão (Q2 - Cite os principais impactos ambientais que podem ser identificados nas áreas onde se concentra a exploração de minérios.) verificou se que a partir das respostas atribuídas pelos entrevistados, existem sérios problemas 
ambientais em regiões exploradas no município de Frei Martinho. O desmatamento (40\%) novamente apareceu como o ponto mais preocupante na região, seguido pelos rejeitos descartados em lugares inapropriados (30\%) e cavas expostas (25\%) (Figura 3).

Figura 3 - Impactos ambientais identificados no município de Frei Martinho - PB, segundo os entrevistados

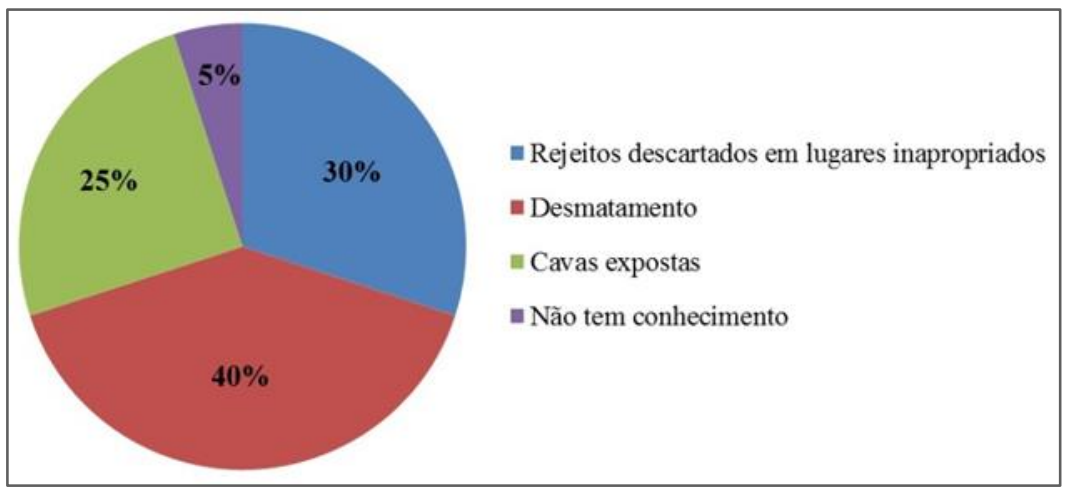

Fonte: Dados da pesquisa, 2018.

Como forma de consolidar algumas questões relacionadas aos impactos ambientais relatados pelos mineradores durante as entrevistas, medidas de divulgação podem ser essenciais neste processo de conscientização. Desta forma, Fernandes e Muniz Filho (2016) sugerem que a exposição de palestras pode ser uma medida eficaz para auxiliar no esclarecimento de alguns termos, como o significado de impacto ambiental, exemplificação dos que ocorrem no próprio garimpo e possíveis medidas para redução e prevenção de alguns desses impactos.

Apesar da problemática que gira em torno dos problemas ambientais que podem ser causados pela mineração, verificou-se em um trabalho realizado por Rabelo (2017), que boa parte da população estudada considera que é possível conciliar mineração e preservação ambiental. Porém, uma parcela da comunidade afirmou que essa conciliação depende, principalmente, de atitudes da empresa, reforçando sua responsabilidade na implantação do empreendimento. 
A terceira questão (Q3 - Quais espécies de plantas são identificadas nas regiões próximas das minas?) tinha como intuito analisar quais espécies vegetais habitam áreas perturbadas pela mineração, e assim, permitir investigações futuras sobre a resistência dessas espécies em adaptar-se às alterações nos solos oriundos de regiões exploradas. As principais espécies citadas pelos mineradores são: Marmeleiro (Croton sonderianus Muell. Arg.); Catingueira (Caesalpinia pyramidalis Tul.); Jurema-preta (Mimosa tenuiflora (Willd.) Poir.); Algarobeira (Prosopis juliflora (Sw.) DC.); Angico (Piptadenia macrocarpa Benth.); Juazeiro (Ziziphus joazeiro Mart.); Umbuzeiro (Spondias tuberosa L.); Xique-xique (Pilocereus floccosus Backeb. \& Voll) e Urtiga (Urtica dioica L.). Pode-se analisar que todas estas espécies citadas pelos entrevistados são plantas típicas da região semiárida nordestina (Figura 4).

Figura 4 - Vegetação localizada próxima as áreas exploradas pelos mineradores. Sítio Quixaba, Frei Martinho - PB

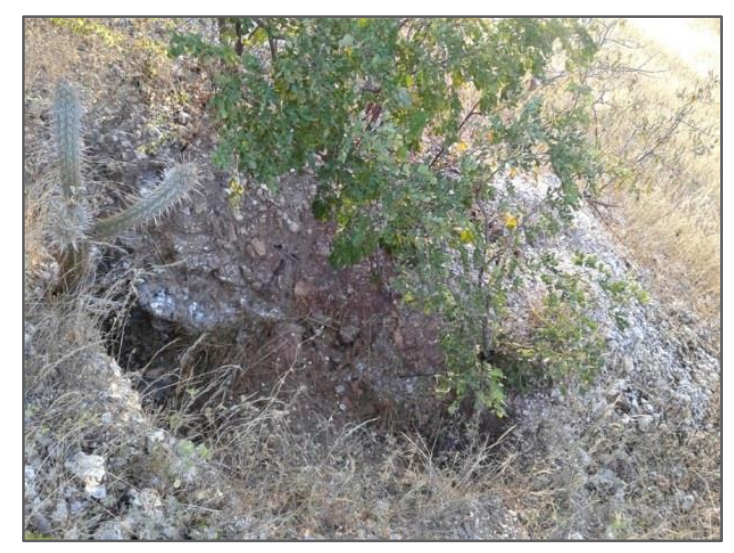

Fonte: Dados da pesquisa, 2018.

De acordo com Andreazza et al. (2013) algumas espécies vegetais são mais resistentes e podem ter uma maior capacidade de extração de metais pesados como o cobre, quando em comparação a outras espécies. Sendo assim, espécies de plantas que têm essa capacidade de extrair metais pesados, são de extrema importância em áreas exploradas pela mineração. Várias discussões em busca de soluções para a resolução de problemas ambientais de forma natural têm impulsionado diversas pesquisas, e com isso, 
inúmeras plantas estão sendo testadas com a finalidade fitorremediadora (AMADO e CHAVES FILHO, 2015).

Quanto a quarta questão (Q4 - Como você avalia o impacto causado pelo barulho dos explosivos sobre a fauna? Você acredita que os animais silvestres podem se afastar da região?) $85 \%$ dos participantes afirmaram que os animais podem se afastar das regiões próximas das minas devido o barulho dos explosivos, enquanto que $15 \%$ relataram que os animais tendem a se adaptar ao barulho (Figura 5).

Figura 5 - Concepções dos mineradores sobre o impacto na fauna local causado pelo som dos explosivos

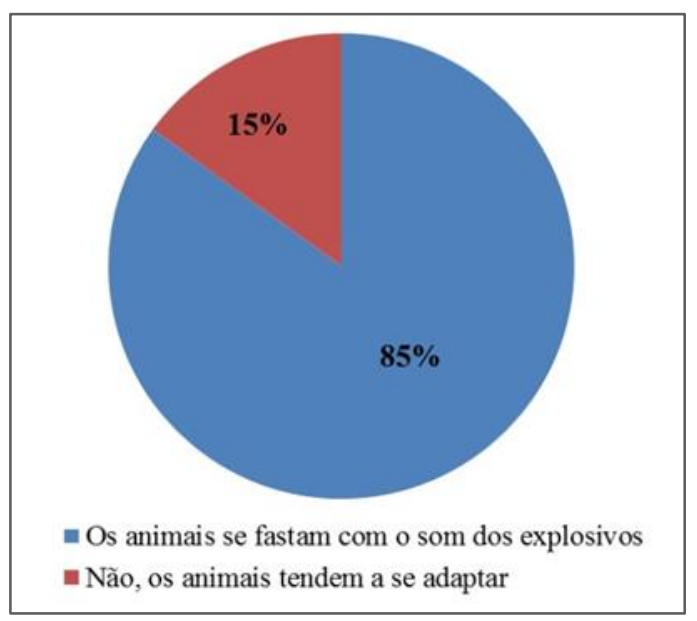

Fonte: Dados da pesquisa, 2018.

Silva (2007) ressalta que a fuga dos animais silvestres tem sido um grave problema ambiental em regiões próximas de minas em funcionamento. Além do barulho dos explosivos que podem influenciar no afastamento da fauna, Carvalho et al. (2015) explicam que as alterações físicas e químicas dos solos, pode afetar diretamente a biodiversidade, causando uma perda significativa da capacidade produtiva.

Sobre a quinta questão (Q5 - Que tipos de rejeitos são descartados pelas minas da região?) os mineradores relataram que os principais rejeitos descartados são: pó ou bagaço de mica; cristal (quartzo); feldspato; berilo; xisto; calcário; carvão ou turmalina preta (afrisita/schorlita), e caulim (Figura 6). Outros entrevistados ressaltaram ainda que 
não há rejeito ou descarte de minerais, pelo seu interesse econômico, todos os minerais dos pegmatitos graníticos da região podem ser aproveitados.

Figura 6 - Descarte de rejeitos resultantes da atividade mineradora. Sítio Quixaba, Frei Martinho - PB

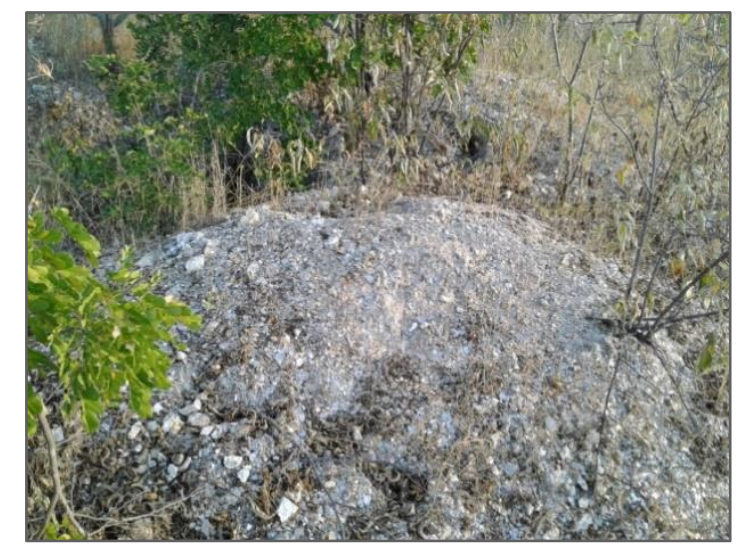

Fonte: Dados da pesquisa, 2018.

Apesar de não ser uma prática comum entre os mineradores participantes desta pesquisa, o aproveitamento dos resíduos da mineração pode ser amplamente utilizado como matéria-prima para outras atividades industriais, e desse modo, parte dos problemas ambientais pode ser resolvida (AMARAL FILHO et al., 2013). Porém, deve-se levar em conta que para se tornar viável o aproveitamento de materiais no módulo de rejeitos é necessário o emprego de técnicas de beneficiamento de minérios, como a classificação granulométrica e a concentração gravimétrica (AMARAL FILHO, 2009). Isso requer um investimento por parte das empresas mineradoras.

Dando continuidade ao que foi abordado na questão cinco, a sexta questão (Q6 - O local onde os rejeitos das minas são descartados oferecem riscos para a fauna e a flora?) buscava saber os riscos que os rejeitos exercem sobre a fauna e a flora da região semiárida. É possível analisar a partir dos relatos dos entrevistados que $75 \%$ têm consciência dos prejuízos causados pela mineração sobre as espécies vegetais e animais que habitam locais próximos das minas. Porém, $25 \%$ dos participantes afirmaram que os rejeitos das minas não oferecem risco ao meio ambiente (Figura 7). 
Figura 7 - Percepções dos mineradores acerca dos riscos que os rejeitos podem causar para a fauna e a flora

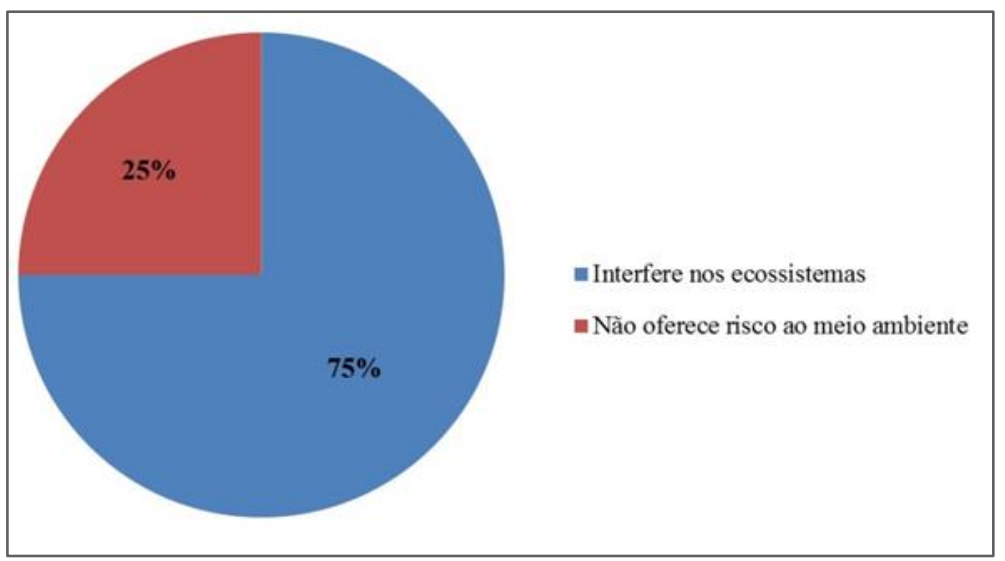

Fonte: Dados da pesquisa, 2018.

Carvalho et al. (2015) explicam que as rochas são retiradas e lapidadas para serem transportadas deixando a flora e a fauna coberta por um pó de rocha que impede a transpiração de plantas e animais. Atividades exploratórias alteram intensamente a área minerada, gerando transformações no meio físico e transformações no meio biótico, com a redução da biodiversidade (SOBRAL et al., 2007). Desta forma, pode-se verificar que as populações de animais e plantas sofrem constantemente com alterações no meio em que vivem.

Um ponto extremamente importante foi abordado na sétima questão (Q7 - Existem meios de divulgação no Município sobre os possíveis impactos ambientais que a mineração pode causar?), e constatou-se que 15 dos 20 entrevistados relataram que não havia nenhum tipo de orientação ou divulgação acerca dos danos que a mineração pode causar nos ecossistemas. Apenas alguns dos mineradores relataram que as empresas e cooperativas ligadas ao setor minerário disponibilizavam palestras e orientações sobre as problemáticas ambientais.

Segundo os entrevistados desta pesquisa, apesar de serem poucas as cooperativas que se preocupam com questões ambientais, é fundamental a existência de empresas que deem ênfase a preservação da natureza. Sendo assim, os gestores devem incentivar e 
apoiar a conscientização ambiental, pois a eles não é dado o direito de ignorar tais princípios (RIBEIRO et al., 2013).

É possível afirmar que além da falta de comprometimento de muitas empresas, ainda existem as questões políticas. Mechi e Sanches (2010) relatam que a falta de ações de planejamento por parte dos poderes públicos têm gerado conflitos relacionadas com outras formas de uso do solo. Além disso, a falta de controle e a não recuperação ambiental satisfatória das áreas mineradas têm causado uma série de outros impactos indesejáveis ao meio ambiente.

Em relação a oitava questão (Q8 - Quais métodos de recuperação das áreas degradadas pela mineração você conhece?) foi possível observar que apesar da falta de divulgação dos problemas ambientais, os mineradores demonstraram ter conhecimento de algumas técnicas eficazes que contribuem para uma melhoria do meio ambiente, onde $80 \%$ dos entrevistados relataram que o reflorestamento pode ser uma medida eficaz para a recuperação de áreas degradas (Figura 8).

Figura 8 - Percepção dos entrevistados acerca dos métodos de recuperação de áreas degradadas

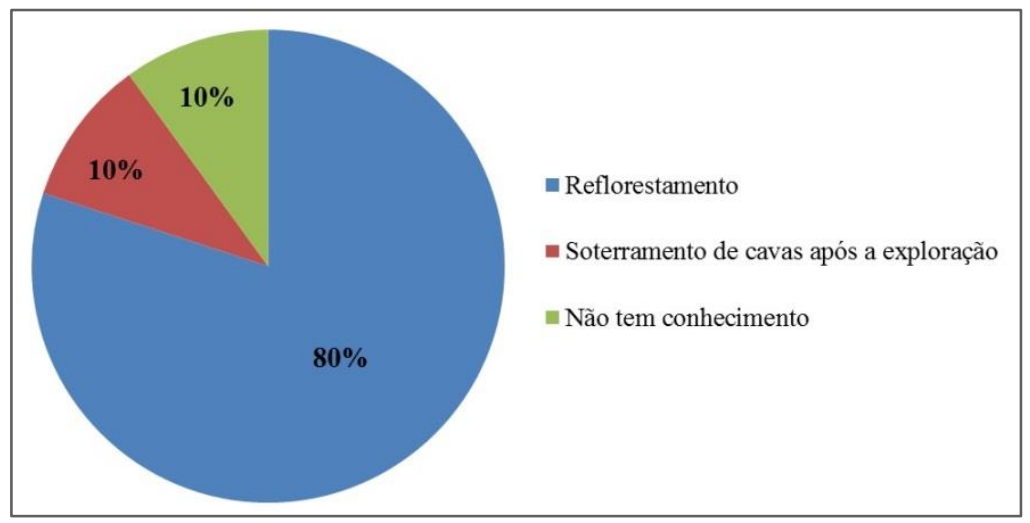

Fonte: Dados da pesquisa, 2018.

Segundo Almeida e Sanchez (2005), o objetivo prioritário da revegetação é alcançar a estabilidade física do local. Em pesquisas desenvolvidas por Regensburger et al. (2008) foi possível constatar espécies oriundas da revegetação natural, onde identificou-se 
representantes de 12 famílias, sendo elas: Asteraceae, Cyperaceae, Poaceae, Euphorbiaceae, Rubiaceae, Solanaceae, Commelinaceae, Myrsinaceae, Phytolacaceae, Polygonaceae, Apiaceae e Laminaceae.

Apesar do conhecimento sobre algumas técnicas de recuperação de áreas degradadas, poucos mineradores afirmaram colocá-las em prática. Foi possível identificar esta falha por meio da nona questão (Q9 - Você utiliza métodos para restaurar áreas que foram afetadas pela mineração?). Apenas $15 \%$ dos participantes relataram usar meios para recuperar áreas que foram degradadas (Figura 9).

Figura 9 - Posicionamento dos entrevistados sobre se eles utilizam métodos para recuperar áreas degradadas

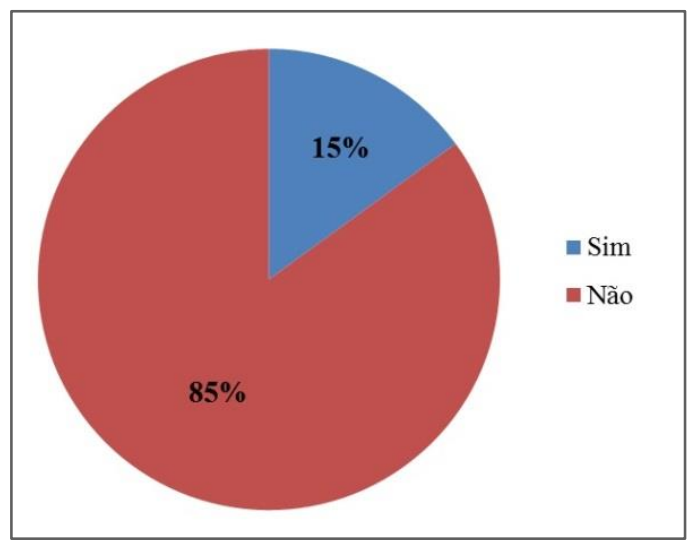

Fonte: Dados da pesquisa, 2018.

Como identificado nesta pesquisa, percebe-se que muitos mineradores (85\%) não utilizam nenhum tipo de método de recuperação de áreas que foram afetadas pela mineração, sendo este um grande problema para o município de Frei Martinho, por isso, deve-se intensificar o apelo para a divulgação de medidas que tenham como base incentivar e auxiliar a população sobre a preservação ambiental. No entanto, o problema toma uma proporção maior quando os órgãos governamentais brasileiros em geral não executam nem fornecem os meios para facilitar a restauração, de modo que os custos, com raras exceções, são de responsabilidade dos proprietários de terras, tanto para os que 
desmataram ilegalmente quanto para os casos de restauração voluntária (DURIGAN et al., 2010).

Para finalizar, a décima e última questão (Q10 - Cite as principais dificuldades para implantar métodos de recuperação de áreas degradadas pela mineração.) buscava um esclarecimento por parte dos entrevistados sobre os principais obstáculos que eles encontram para colocar em prática algumas medidas para reverter os danos causados pela mineração na natureza e constatou-se que $59 \%$ dos pequenos mineradores relataram que a falta de investimentos é o maior problema para recuperar áreas degradadas. A falta de planejamento (23\%) e o custo financeiro elevado (10\%) também foram destacados na entrevista (Figura 10).

Figura 10 - Dificuldades citadas pelos mineradores para recuperar áreas degradadas pela mineração

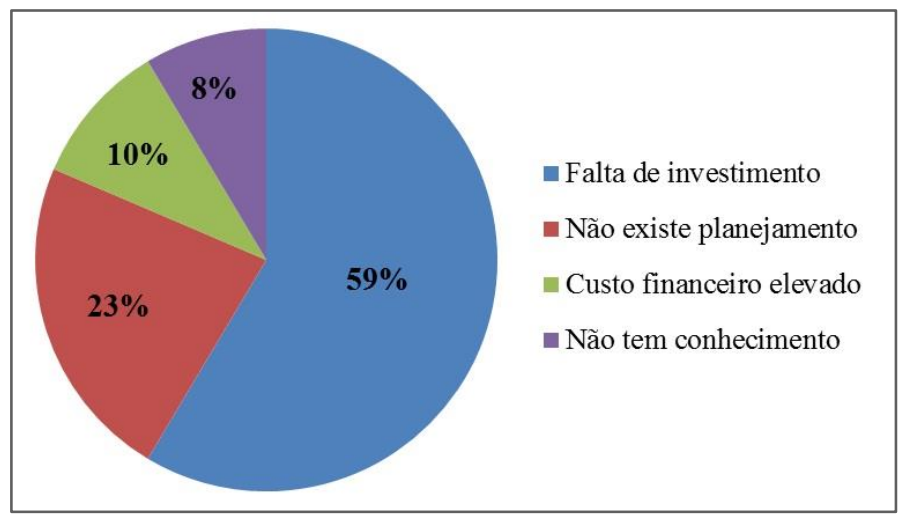

Fonte: Dados da pesquisa, 2018.

As dificuldades relatadas pelos mineradores durante as entrevistas são consideradas extremamente relevantes, e por isso é necessário buscar soluções plausíveis para a resolução do problema em questão. No que se diz respeito as tecnologias criadas para auxiliar no processo de recuperação de áreas afetadas pela mineração, compreende-se que muitas delas envolve custos adicionais aos projetos, sejam estaduais ou privados, de companhias nacionais ou multinacionais, ou empreendimentos de garimpo, que nem sempre se mostram acessíveis a internalizar estes custos (SILVA, 2005). A mecanização 
também é um importante meio para facilitar os processos envolvidos com recuperações de áreas degradadas, porém, poucas publicações no país relatam a viabilidade da mecanização e sua importância nos processos ambientais (RIBEIRO et al., 2004).

\section{CONCLUSÕES}

A partir das informações obtidas por meio dos relatos dos entrevistados, verificouse que existem vários impactos ambientais causados pelas atividades mineradoras no município de Frei Martinho - PB. Além disso, constatou-se também que os pequenos mineradores demonstraram um conhecimento superficial sobre o assunto abordado, sendo necessária a realização de palestras e outros meios de conscientização por parte das empresas e cooperativas responsáveis pela mineração no referido município.

É importante destacar que os mineradores tem conhecimento de algumas técnicas importantes para a recuperação de áreas degradadas pela mineração, porém, apenas alguns dos entrevistados relataram colocar em prática métodos como o reflorestamento que auxiliam de forma direta no processo de reestabelecimento da flora da região afetada. Desta forma, a falta de investimentos por parte dos responsáveis pela mineração em Frei Martinho - PB para restaurar áreas degradadas, é um problema que deve ser corrigido urgentemente.

Por fim, conclui-se que o presente trabalho gerou dados suficientes para que novas pesquisas sejam realizadas na região. Tomando-se como base as informações fornecidas pelos entrevistados, seria importante a execução de um diagnóstico posterior para avaliar e descrever os principais impactos causados pela mineração nos ecossistemas terrestres e aquáticos de Frei Martinho - PB.

\section{REFERÊNCIAS}

ALMEIDA, R. O. P. O.; SÁNCHEZ, L. E. Revegetação de áreas de mineração: critérios de monitoramento e avaliação do desempenho. Revista Árvore, v. 29, n. 1, p. 47-54, 2005. 
AMADO, S.; CHAVES FILHO, J. T. Fitorremediação: uma alternativa sustentável para remedição de solos contaminados por metais pesados. Revista Natureza Online, v. 13, n. 4, p. 158-164, 2015.

AMARAL FILHO, J. R. Avaliação ambiental e do potencial de aproveitamento de um módulo de rejeitos de carvão na região carbonífera de Santa Catarina. Dissertação (Mestrado em Engenharia de Minas, Metalúrgica e de Materiais). Porto Alegre: Universidade Federal do Rio Grande do Sul. 79p. 2009.

AMARAL FILHO, J. R.; SCHNEIDER, I. A. H.; BRUM, I. A. S.; SAMPAIO, C. H.; MILTZAREK, G.; SCHNEIDER, C. Caracterização de um depósito de rejeitos para o gerenciamento integrado dos resíduos de mineração na região carbonífera de Santa Catarina, Brasil. Rem: Revista Escola de Minas, v. 66, n. 3, p. 347-353, 2013.

ANDREAZZA, R.; CAMARGO, F. A. O.; ANTONIOLLI, Z. I.; QUADRO, M. S.; BARCELOS, A. A. Biorremediação de áreas contaminadas com cobre. Revista de Ciências Agrárias, v. 36, n. 2, p. 127-136, 2013.

ANNIBELLI, M. B.; SOUZA FILHO, C. F. M. Mineração de areia e seus impactos sócioeconômicoambientais. In: Congresso Nacional do CONPEDI. p. 4205-4217, 2006.

ASSIS, H. F. S.; BARBOSA, J. A. A.; MOTA, T. S. Avaliação dos impactos ambientais provocados pela atividade mineradora no município de Pedra Lavrada-PB. Revista Âmbito Jurídico, v. 14, n. 90, 2011.

CARVALHO, J. R. M.; CARVALHO, E. K. M. A.; CURI, W. F. Sustentabilidade ambiental no setor de mineração no município de Vieirópolis, PB: estudo de caso com aplicação do modelo PressãoEstado-Resposta. Ambiente \& Educação - Revista de Educação Ambiental, v. 20, n. 1, p. 87-103, 2015.

DURIGAN, G.; ENGEL, V. L.; TOREZAN, J. M.; MELO, A. C. G.; MARQUES, M. C. M.; MARTINS, S. V.; REIS, A.; SCARANO, F. R. Normas jurídicas para a restauração ecológica: uma barreira a mais a dificultar o êxito das iniciativas?. Revista Árvore, v. 34, n. 3, p. 471-485, 2010.

FERNANDES, S. S.; MUNIZ FILHO, P. Educação ambiental enquanto instrumento para redução de impactos ambientais em garimpos. Revista Práxis: saberes da extensão, v. 4, n. 6, p. 59-66, 2016.

FREITAS, H.; OLIVEIRA, M.; SACCOL, A. Z.; MOSCAROLA, J. O método de pesquisa Survey. Revista de Administração, São Paulo, v. 35, n. 3, p. 105-112, 2000.

GUIMARÃES, C. L.; MILANEZ, B. Mineração, impactos locais e os desafios da diversificação: revisitando Itabira. Desenvolvimento e Meio Ambiente, v. 41, p. 215-236, 2017. 
IBGE - Instituto Brasileiro de Geografia e Estatística. Disponível em: https://cidades.ibge.gov.br/brasil/pb/frei-martinho/panorama. Acesso em 10 de dez. 2017.

MANOEL, L. O.; OLIVEIRA, M.; CARVALHO, S. L. Percepção ambiental da população ribeirinha no porto de navegação no município de Ilha Solteira/SP. Revista Científica ANAP Brasil, v. 6, n. 7, 2013.

MARTIM, H. C.; SANTOS, V. M. Avaliação de impactos ambientais em empresa de mineração de cobre utilizando redes de interação. Revista Eletrônica em Gestão, Educação e Tecnologia Ambiental, v. 17, n. 17, p. 3246-3257, 2013.

MECHI, A.; SANCHES, D. L. Impactos ambientais da mineração no Estado de São Paulo. Estudos avançados, v. 24, n. 68, p. 209-220, 2010.

PATRÍCIO, M. C. M.; SILVA, V. M. A.; RIBEIRO, V. H. A. Conflitos socioambientais: estudo de caso em uma pedreira na Paraíba. Revista POLÊM!CA, v. 12, n. 3, p. 528-544, 2013.

PONTES, J. C. de; FARIAS, M. S. S. de; LIMA, V. L. A. de. Mineração e seus reflexos socioambientais: Estudo de Impactos de vizinhança (EIV) causados pelo desmonte de rochas com uso de explosivos. Revista POLÊM!CA, v. 12, n. 1, p. 77-90, 2013.

RABELO, A. M. P. Qualidade ambiental e mineração: percepção de moradores de Carmo da Mata/MG. Pesquisa em Educação Ambiental, v. 12, n. 1, p. 129-145, 2017.

REGENSBURGER, B.; COMIN, J. J.; AUMOND, J. J. Integração de técnicas de solo, plantas e animais para recuperar áreas degradadas. Ciência Rural, v. 38, n. 6, p. 1773-1776, 2008.

RIBEIRO, A. I.; LONGO, R. M.; MACIEL, A. J. S.; MELLO, W. J. Produção operacional de equipamentos na recomposição topográfica de áreas degradadas por exploração mineral na floresta nacional do Jamari, Estado de Rondonia, Brasil. Engenharia Ambiental: Pesquisa e Tecnologia, v. 1, n. 1, p. p. 65-72, 2004.

RIBEIRO, G. F.; CARLESSO, R. E. C.; OLIVEIRA, M. E. Conscientização ambiental na empresa auto elétrica GF, no município de Marcelândia - MT. Revista Eletrônica da Faculdade de Alta Floresta, v. 2, n. 1, p. 77-102, 2013.

SILVA, E. F. G. Análise da implementação dos planos de recuperação de áreas degradadas pela mineração em Lourenço (AP). Dissertação (Mestrado em Planejamento do Desenvolvimento). Belém: Universidade Federal do Pará. 175p. 2005.

SILVA, J. P. S. Impactos ambientais causados por mineração. Revista espaço da Sophia, v. 8, p. $1-13,2007$. 
SOBRAL, I. S.; SANTANA, R. K. O.; GOMES, L. J.; RIBEIRO, G. T.; SANTOS, J. R.; COSTA, M. Avaliação dos impactos ambientais no Parque Nacional Serra de Itabaiana-SE. Caminhos de Geografia, $v$. 8, n. 24, p. 102-110, 2007.

VIEIRA, E. G.; REZENDE, E. N. Mineração de areia e meio ambiente: é possív possível harmonizar?. Revista do Direito Público, v. 10, n. 3, p. 181-212, 2015.

WANDERLEY, L. J.; MANSUR, M. S.; MILANEZ, B.; PINTO, R. G. Desastre da Samarco/Vale/BHP no Vale do Rio Doce: aspectos econômicos, políticos e socioambientais. Ciência e Cultura, v. 68, n. 3, p. 30-35, 2016. 